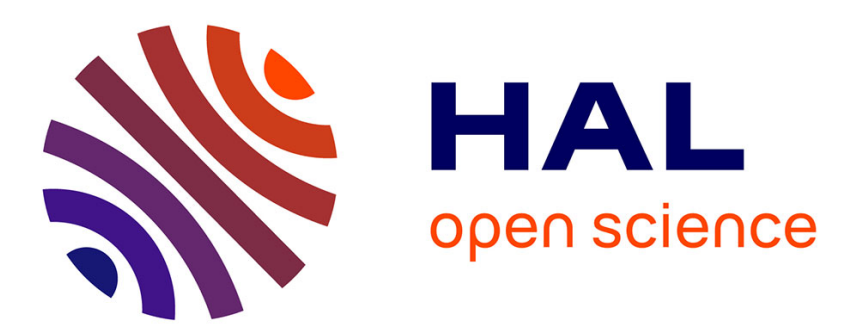

\title{
Generalized Pareto Distribution for reliability of bridges exposed to fatigue
}

\author{
Mariia Nesterova, Franziska Schmidt, Eugen Brühwiler, Christian Soize
}

\section{To cite this version:}

Mariia Nesterova, Franziska Schmidt, Eugen Brühwiler, Christian Soize. Generalized Pareto Distribution for reliability of bridges exposed to fatigue. IABMAS 2018, Conference on Bridge Maintenance, Safety and Management, Jul 2018, Melbourne, Australia. 8 p. hal-01855810v2

\section{HAL Id: hal-01855810 \\ https://hal.science/hal-01855810v2}

Submitted on 12 Mar 2021

HAL is a multi-disciplinary open access archive for the deposit and dissemination of scientific research documents, whether they are published or not. The documents may come from teaching and research institutions in France or abroad, or from public or private research centers.
L'archive ouverte pluridisciplinaire HAL, est destinée au dépôt et à la diffusion de documents scientifiques de niveau recherche, publiés ou non, émanant des établissements d'enseignement et de recherche français ou étrangers, des laboratoires publics ou privés. 


\title{
Generalized Pareto Distribution for reliability of bridges exposed to fatigue
}

\author{
M. Nesterova \\ Université Paris-Est, SDOA, MAST, IFSTTAR, Marne-la-Vallée, France
}

F. Schmidt

Université Paris-Est, SDOA, MAST, IFSTTAR, Marne-la-Vallée, France

E. Brühwiler

MCS, EPFL, Lausanne, Switzerland

C. Soize

Université Paris-Est, MSME UMR 8208, Marne-la-Vallée, France

ABSTRACT: To assess the reliability of existing bridges, in general, extreme effects on a structure are analyzed, which allows predicting their behavior. In particular cases of small bridges, effects caused by fatigue due to the cyclic traffic loading might be significant. The main interest of the current paper is the possibility of applying the extreme value analysis to dissimilar bridges using data from different types of monitoring. Research in this area is carried out on the Anneau bridge in Switzerland and on the Millau viaduct, France, in order to compare the fatigue behavior based on signals from strain gauges in one case and on the WIM data in the other. The estimation of the fatigue life is based on the Extreme Value Theory and, in particular, the Generalized Pareto Distribution. The results aid to derive the efficiency of the method for the predictions of the high cycle fatigue action.

\section{INTRODUCTION}

The complexity of predicting the behavior of such structures as bridges at the end of their design life is an important topic for modern research. Due to the fact that many European bridges, as well as bridges all over the world, are coming to the end of their design life, the question of the extension of their operational life is vital. Moreover, the study of such objects allows improving design rules for future structures and possibly some profit from an economic point of view.

Usually, in bridge engineering, for the forecasting of the return levels of actions within the time period of the interest, the Extreme Value Theory (EVT) is used (Coles et al. 2001) such as for background works on Eurocodes (Sedlacek et al., 2008). One of the most efficient approaches to be used is the Peaks Over Threshold (POT), which proved to work well in diverse fields: wind engineering (Agarwal \& Lance, 2009), precipitation predictions with nonstationary data (Roth et al. 2014), electricity demand estimation with a time-varying threshold (Sigauke \& Bere, 2017) and others.

Concerning bridges, the mentioned method is successfully used to envision the forthcoming situation with an object (Zhou, 2013, Treacy, 2014), based on the long-term monitoring of traffic actions. For the proper use of the EVT, usually only extreme, meaning the highest, actions are considered. For instance, heavy (even overweighted) trucks are taken into account without paying attention to light cars.
Since the number of light duty vehicles in most cases is quite large, they may cause fatigue of certain elements of a bridge. An interesting question is if this case can significantly affect the structure and how to anticipate it. Therefore, the focus of the current paper is mainly on the fatigue loading.

The interest of this study lays in fitting the generalized Pareto distribution (GPD), as a principal distribution of the POT approach, to the distribution of the number of fatigue cycles caused by different vehicles and axles of trucks. There were several similar studies carried out in various areas. For instance, in the area of composites, the stiffness-based model is introduced by (Shiri et al. 2016) for fatigue damage and life prediction or (Adasooriya, 2016) compares a new probabilistic fatigue assessment approach with a deterministic approach for railway bridges.

As it was recently proposed (Cetin, 2013), the different aspects of material fatigue may be considered as an extreme value dependent process. For a certain observed object, it is important to understand which case is the most unfavorable for a bridge: high amplitude stresses caused by rare extreme events or small stresses by a high number of cycles.

\section{METHODOLOGY}

\subsection{General procedure}

In general, to estimate the probability of occurrence of certain load effects (return level) within specified 
periods of time (return period), the EVT might be applied to structures or structural elements.

First of all, it is necessary to choose an element in the studied structure that is exposed to the most unfavorable action or combination of actions. For example, in a case of bridges, it can be an element in the middle of a long span, where the bending moment is high. For reinforced concrete bridges, the main interest would be in those rebars with higher tensile stresses; for steel bridges, it might be the bottom flange of the girder, in details, welded parts.

Then, recorded data are needed to make predictions of the future behavior of a structure. One of the possibilities is measurements by strain gauges installed on the surfaces of the observed elements. Several gauges installed at different levels can help to get the stress redistribution in a cross-section. The frequency of measurements is important to obtain correct values of stresses from the measured strain. For instance, in bridges, to detect passing cars, the frequency of $50 \mathrm{~Hz}$ can be sufficient. The length of monitoring is not recommended to be less than 3 months in a case of traffic loads (Treacy, 2014) due to the instability of predictions.

Usually, such measurements are used to apply EVT based on block maxima or threshold models (Coles, 2001), where only extreme effects are considered. Data are fitted, respectively, to generalized extreme value distribution (GEVD) or GPD with certain parameters. These parameters are used to estimate return levels. To identify extreme values of load effects (LEs) represented, in this case, by fatigue cycles, the POT method is used as it is briefly shown in Figure 1.

\subsection{Common use of GPD}

It has been recently adopted for predictions of extreme traffic actions (Zhou, 2013, Zhou et al. 2016). Peak values of LEs $X_{i}$ that lay above a certain threshold $u$ are fitted to the GPD. The conditional distribution function can be expressed as:

$F_{u}(y)=P[Y \leq y \mid X>u]=\frac{F(y+u)-F(u)}{1-F(u)}$

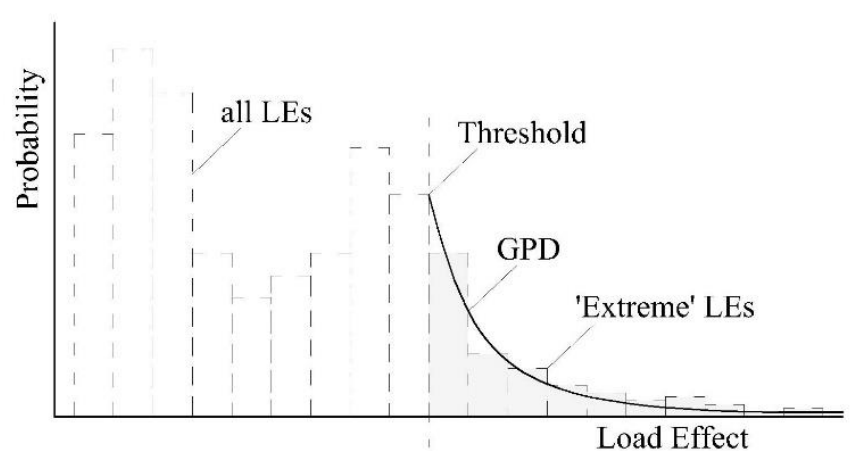

Figure 1. Representation of the POT approach where $Y=X-u$ is a vector of (positive) threshold excesses $Y_{i}$, so that $Y_{i}=X_{i}-u$ and $F(u)$ is the cumulative distribution function of random variable $X$.

The main principe of the POT approach is based on the method described by (Pickands, 1975) and applied later for traffic loads: $F_{u}(y)$, under mentioned assumptions and conditions: $y=x-u, y \geq$ $0, \sigma>0$ and $x \geq u$ for $\xi \geq 0, u \leq x \leq u-\sigma / \xi$ for $\xi<0$; tends to the upper tail of a GPD:

$G(x ; \xi ; \sigma ; u)= \begin{cases}1-\left[1+\xi\left(\frac{x-u}{\sigma}\right)\right]^{-\frac{1}{\xi}}, & \xi \neq 0 \\ 1-\exp \left(-\frac{x-u}{\sigma}\right), & \xi=0\end{cases}$

Conditions for the application of the EVT are the following:

- identical distribution of random variables $X_{i}$,

- random variables $X_{i}$ are independent,

- threshold $u$ is necessarily high.

For a long period, observations can be based on the cumulative distribution function of extreme values over a shorter period (Crespo-Minguillon \& Casas, 1997).

Provided by (Coles et al. 2001), for the probability $P[X \leq x \mid X>u]$ with $\zeta_{u}=P\{X>u\}$, the solution to the function is:

$R_{L}(\mathrm{p})= \begin{cases}u+\frac{\sigma}{\xi}\left[\left(p \zeta_{u}\right)^{\xi}-1\right], & \xi \neq 0 \\ u+\sigma \log \left(p \zeta_{u}\right), & \xi=0\end{cases}$

where $R_{L}(\mathrm{p})$ is p-observation return level - a quantile that exceeds once every $\mathrm{p}$ observations with large enough $\mathrm{p}$ to provide $R_{L}(\mathrm{p})>u$.

The POT approach has also its difficulties such as selecting of an optimized threshold. On one side, it should be reasonably high, so, that extreme event types are not mixed, in order to avoid their convergence. On the other side, the threshold must be low enough to provide a necessary number of peaks for obtaining reliable results. The correct choice of parameter estimators $\sigma, \xi$ for the GPD is also a drawback of the approach.

\subsection{Case of fatigue cycles}

In order to prove that there is no fatigue in an existing structure, European norms (EN 1993-1-1) provide S-N curves for diverse steel details or elements, and it is stated that there is no any danger under the value of five millions cycles of constant fatigue loading. Recent simulations bring the endurance limit in certain cases up to ten millions cycles (Baptisa, 2017).

Traffic actions on bridges are not constant as small frequent cycles are followed by high amplitude cycles rather randomly. There were 
several recent studies focused on the fatigue simulation on bridges based on measurements. (Donghuang, 2017, Echard, 2013).

In the current study, the following suggestion is made: fitting of the GPD to a distribution of fatigue cycles, caused by vehicles or axles of different weights (Fig. 3). In certain cases, the proposed method takes into account all traffic actions on a bridge, though, the threshold $u$ from the described previously approach is simply equal to zero.

The main idea is to verify the possibility and the efficiency of applying such method to predict the level of the fatigue of bridges (or their structural elements) due to high cycle fatigue load. Here, the term 'high cycle fatigue' is used to determine the cycles from frequent light vehicles.

The use of the GPD with its shape and scale parameters makes it be possible to assess values of return levels of fatigue cycles for different levels of loading. Taking into account that $u=0$, the formula of the return level takes the following format:

$R_{L}(\mathrm{p})= \begin{cases}\frac{\sigma}{\xi}\left[(p \zeta)^{\xi}-1\right], & \xi \neq 0 \\ \sigma \log (p \zeta), & \xi=0\end{cases}$

where $\zeta=P\{X>0\}$ is the probability of a positive $X$ which is valid for all ELs in this case as number of cycles is always a positive value.

Normally, the value of $\zeta_{\mathrm{u}}$ can be found as a ratio between all 'extreme' LEs - values that lay over a threshold $u$ - and all LEs. Considering that all cycles are taken into account, this probability should be $\zeta=1$ which would give the return level of a maximum number of cycles $N_{\text {tot }}$. On the other hand, knowing the probability of a number of cycles $N_{i}$ for each range $\Delta_{i}$ of LEs $\zeta_{i}=N_{i} / N_{t o t}, \sum \zeta_{i}=1$, return levels are estimated for each $\Delta_{i}$ that gives the prediction of the distribution of cycles at the return period of the interest. So, the procedure consists of a few steps shown in Figure 2. The proposed algorithm is applied to monitoring data from two European bridges of totally different geometry and usage.

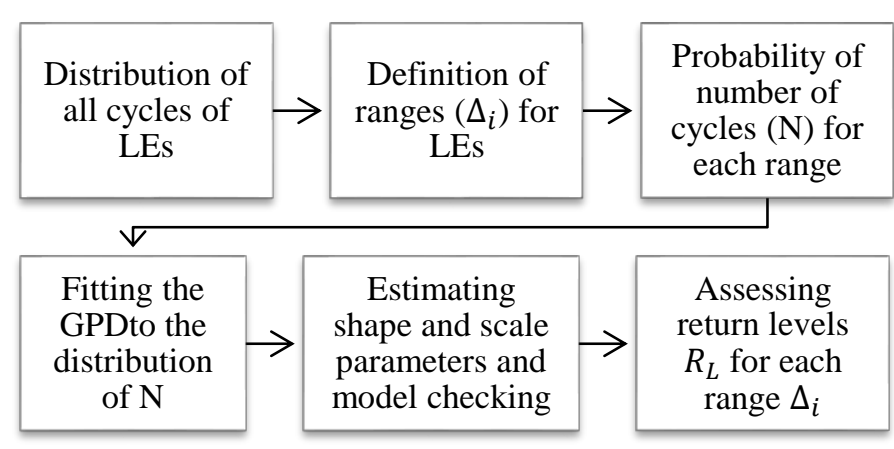

Figure 2. The algorithm of the proposed method

\section{CASE STUDIES}

Results of the study of the following bridges are shown in the current paper:

- Millau Viaduct, France,

- Anneau viaduct, Switzerland.

Each bridge has the specific equipment, as well, a particular geometry, materials and loading levels. In addition, a different type of monitoring was used in each country: Weight-In-Motion (WIM) system in France, strain gauges - in Switzerland.

\subsection{Millau Viaduct}

The viaduct itself is a large structure of $2460 \mathrm{~m}$ long with pylons of 77 to $245 \mathrm{~m}$ high with the height of towers of almost $90 \mathrm{~m}$ (Fig. 2). Its orthotropic steel deck suspended by cables is stiff and provided with joints that permit openings up to $80 \mathrm{~cm}$ in horizontal directions. Each span of $245 \mathrm{~m}$ is composed of six meters long elements, each of them works almost as a simply supported beam. That allows assessing local effects in the complex structure of the bridge.

The final period of 180 days of data was obtained from the WIM system. Recordings were made between October 2016 and July 2017 with a few interruptions.

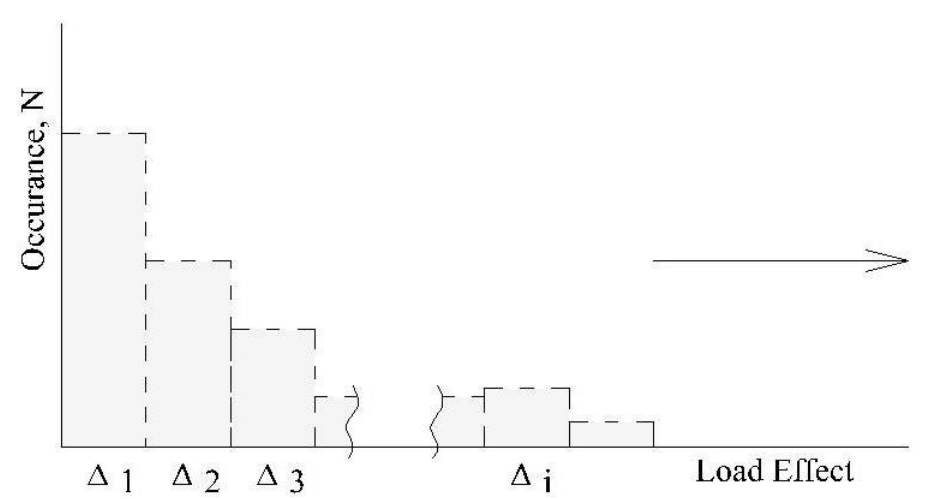

Figure 3. Fitting the GPD to N, number of cycles

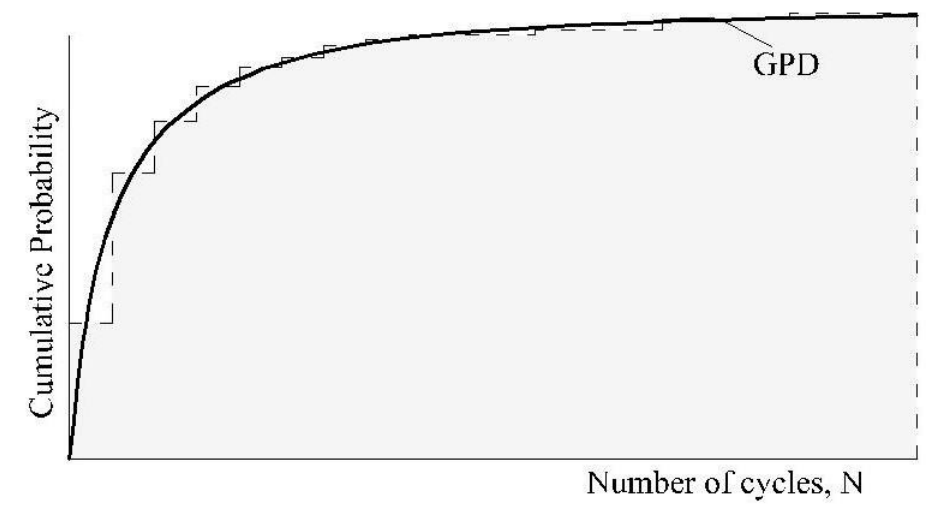




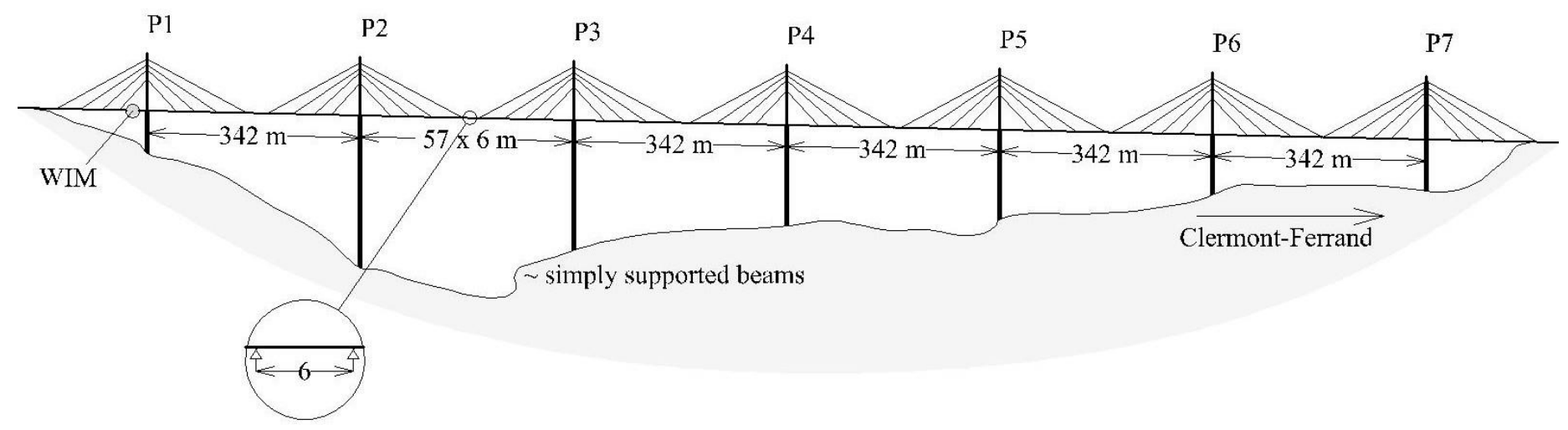

Figure 4. Millau Viaduct

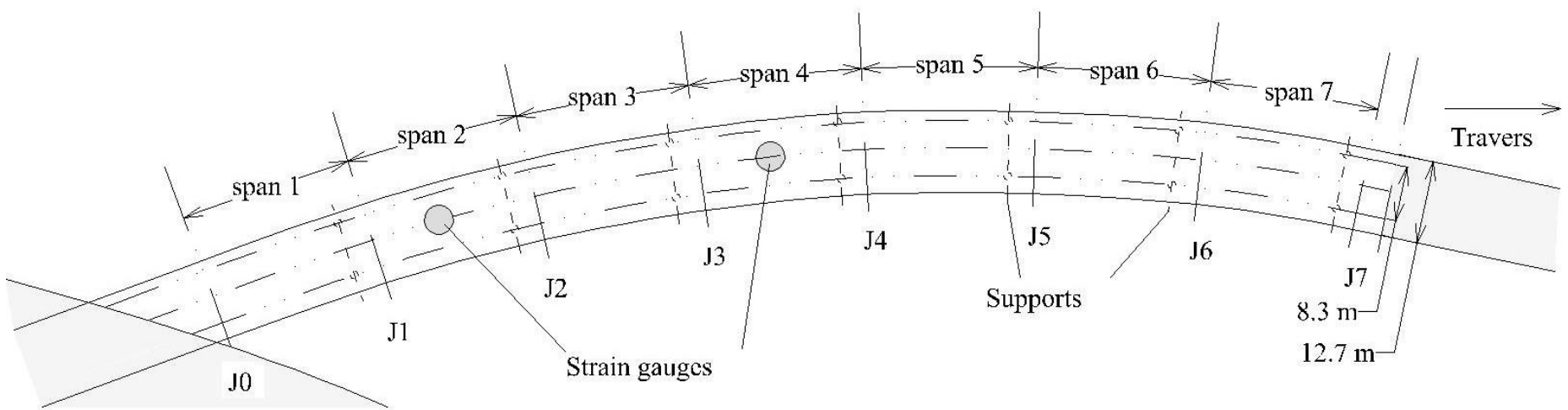

Figure 5. Anneau bridge

The system itself was located in the middle of the first span of the viaduct and recorded all trucks passing the bridge: their weights, speeds, dimensions. The deck of the bridge has two lanes in each direction - normal and high-speed. Monitoring was done only in one, more heavily loaded direction, which does not allow precise evaluating of effects on the viaduct, however, permits to use recorded data for the mathematical model and to make theoretical predictions in terms of LEs given by bending moments.

Table 1. Example of vehicles types

\begin{tabular}{|c|c|c|c|c|c|c|}
\hline \multirow[t]{2}{*}{$\mathrm{N}$} & \multirow{2}{*}{$\begin{array}{l}\text { Vehi- } \\
\text { cle } \\
\text { type }\end{array}$} & \multirow{2}{*}{$\begin{array}{l}\text { Num- } \\
\text { ber of } \\
\text { axles }\end{array}$} & \multicolumn{4}{|c|}{ Distance between axles, $\mathrm{m}$} \\
\hline & & & $\begin{array}{l}1 \text { and } \\
2\end{array}$ & $\begin{array}{l}2 \text { and } \\
3\end{array}$ & $\begin{array}{l}3 \text { and } \\
4\end{array}$ & $\begin{array}{l}4 \text { and } \\
5\end{array}$ \\
\hline 1 & 113 & 5 & 3.64 & 5.50 & 1.27 & 1.23 \\
\hline 2 & 40 & 2 & 5.27 & - & - & - \\
\hline 3 & 61 & 4 & 3.69 & 6.73 & 1.31 & - \\
\hline 4 & 100 & 3 & 8.7 & 3.61 & 5.1 & - \\
\hline 5 & 56 & 3 & 6.8 & 1.46 & - & - \\
\hline
\end{tabular}

Table 2. Axle weights

\begin{tabular}{lllllll}
\hline $\mathrm{N}$ & $\begin{array}{l}\text { Group of } \\
\text { axles }\end{array}$ & \multicolumn{6}{l}{ Weight of each axles, $\mathrm{kN}$} \\
\cline { 3 - 7 } & 113 & 15 & 2 & 3 & 4 & 5 \\
\hline 1 & 11 & 41 & 119 & & 17 & 17 \\
\hline 2 & 112 & 32 & 139 & 34 & 34 & - \\
\hline 3 & 111 & 46 & 65 & 5 & - & - \\
\hline 4 & 12 & 78 & 142 & 142 & - & - \\
\hline 5 & & & & & & \\
\hline
\end{tabular}

Figure 4 shows the scheme of the viaduct with the place of the installed WIM system. Tables $1 \& 2$ give categories of vehicles recorded on the bridge with an example of recordings.

\subsection{Anneau bridge}

The viaduct consists of seven composite steelconcrete spans of $25.6 \mathrm{~m}$ (two steel box girders and a reinforced concrete deck slab). There are only two lanes - one in each direction. Strain gauges were installed directly on the reinforcement bars in transversal and longitudinal directions of the deck slab in the middle of the second and the forth spans (Fig. 5), as well as at the top and the bottom of a steel girder.

For each case, a pair of strain gauges was installed to record signals under the central line of the bridge and close to the middle of the lane. The highest values of stresses were obtained in the transversal reinforcement bars of the span 2, which makes this exact detail an object for the study.

Measurements of the strain have been done for one year (August 2016 to July 2017) with only short interruptions which provides almost one full year of monitoring. Moreover, strain gauges allow assessing load effects (stresses) directly, see Section 4.2. 


\section{APPLICATION OF THE GPD TO THE MONITORING DATA}

\subsection{Millau Viaduct}

First, speaking about fatigue of a bridge, stresses and number of cycles for each stress range are needed. Therefore, critical elements subjected to fatigue loading have to be chosen. In the case of the Millau bridge, values of stresses in the deck are not measured directly. Therefore, it is impossible to observe the presence of dynamic effects; however, the estimation of fatigue is still achievable by using the results of WIM measurements. The system provides not only total weights of each vehicle but also the weight of each axle and distances between them.

Using long-term WIM data for evaluation of fatigue is possible even though it does not give stress cycles directly. Since the system provides forces from each axle of every passing truck that gives stress cycles in elements of the deck. Knowing the exact action applied to the bridge stress in the whole cross-section might be evaluated, in this study, cycles are defined in terms of actions.

There are different combinations of axles possible: some of them are grouped by two or three, as it was demonstrated in Table 1. Assuming that the average distance between axles in a group is $d x<3 m$, and using the recorded distances $d x$ between each pair of axles, all recorded types of vehicles are counted and shown on the pie chart (Fig. 6). As it can be observed from the chart, the most frequent vehicle type is the one with five axles where three last are grouped together.

The value of the stress given by a group of axles is usually higher than the one caused by each axle separately and lower than their sum. So, in this case, to calculate cycles, the common action of three axles have to be considered. Also for the types 112, 12, 122 and 1211, the group of two axles should be taken into account.

As it can be found on Figure 7, P1, P2 and P3 are point loads from each axle of the group of three axles, and $\mathrm{P} 1 *, \mathrm{P} 2^{*}$ and $\mathrm{P} 3^{*}$ are moments that can be obtained theoretically if each axle would pass the span individually. So, it is necessary to take into account that for the response of the structure, there is an influence between axles in groups of two or three. It could be performed theoretically as two or three point loads, presenting on the 6-meters span at the same time.

As it was mentioned in the Section 3.1, the current study is focused on local effects, therefore, 6meters elements of the first span of the deck are considered. For simplicity, influence lines are obtained as the ones for the simply supported beam (Fig. 7).

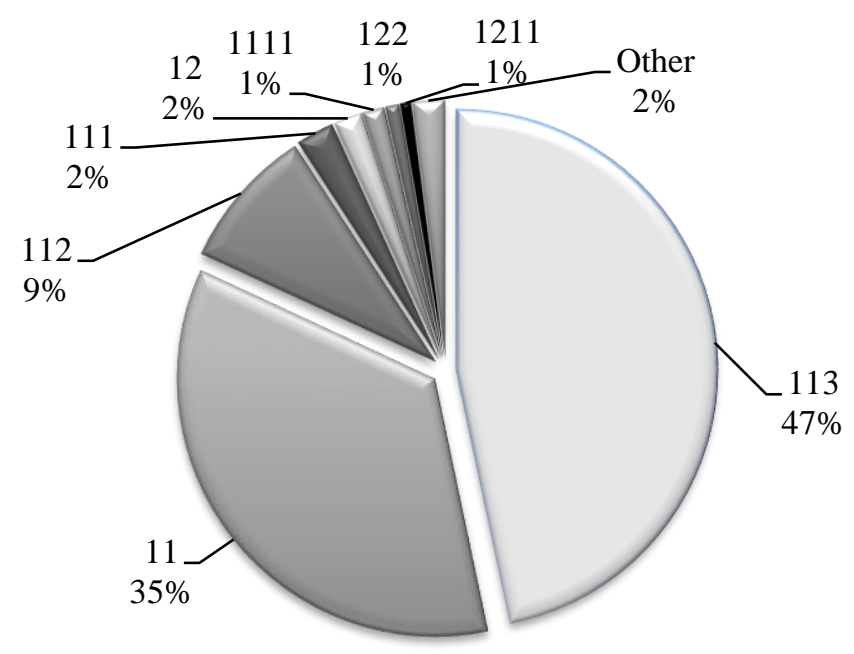

Figure 6. Main types of axles groups

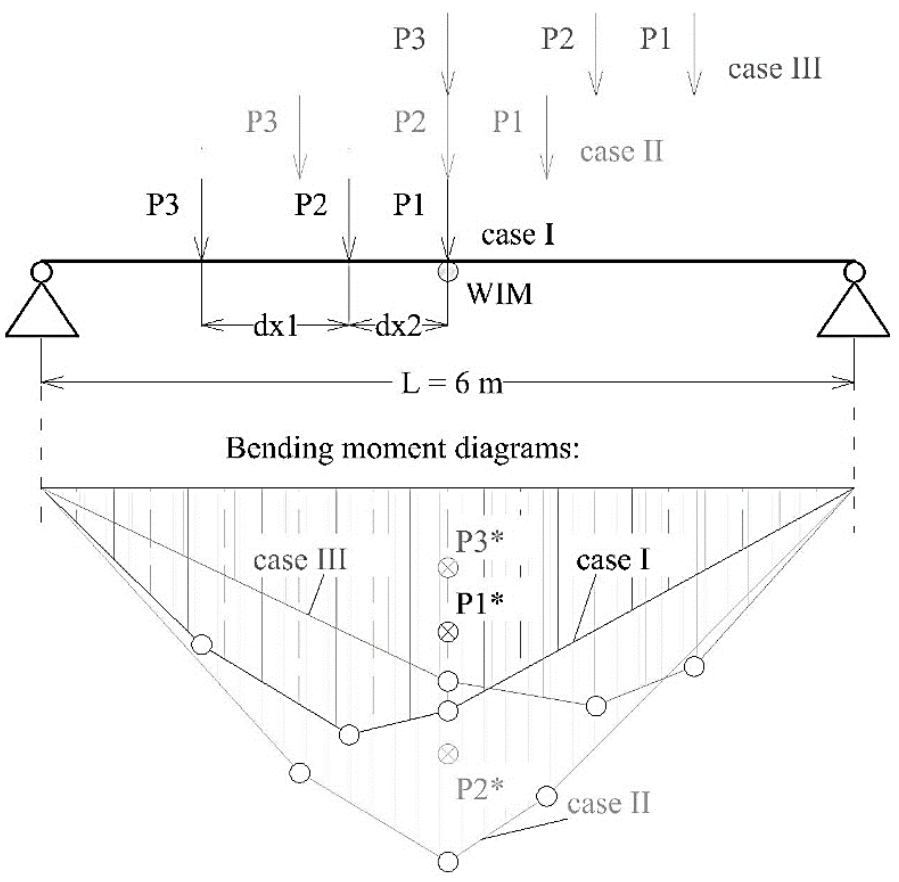

Figure 7. Bending moment from a 3-axles group

This gives the absence of the bending moment (or the values are neglectable) at "supports" - connections between each span. So, for large distances between single axles of vehicles, a weight of each axle can be taken separately as there is almost no influence in terms of stresses. However, for the groups of axles, different values of bending moments are considered as for two or three point loads.

Due to the absence of direct measurements of stresses in any part of the deck, cycles for fatigue are proposed by values of bending moments in the middle of the 6-meters-span, where WIM system was installed. Influence lines for a whole structure can be applied in order to assess bending moments in other parts of the bridge if needed. As well, stresses can be evaluated in the whole cross-section. Here, for simplicity, only measured actions (bending moments) are studied. 
As the most frequent vehicles are 113, 11 and 112 , bending moments in the midspan are calculated only for single, double and triple axles, as following:

- Single point load $P_{I}$ is considered if the distance between axle $I$ and other axles is larger than $L_{\text {span }} / 2=3 m$,

- Double axles are presented by two point loads $P_{I I}$, when the distance between them is smaller than $3 \mathrm{~m}$; the maximum moment is obtained from both positions: either $P_{I I-1}$ or $P_{I I-2}$ above the center,

- Triple axle load is given by three point loads $P_{I I I}$ with three possible positions - each of them at the midspan one by one.

The exceptional combinations of axles removed from the calculations as not reliable. The main point here is to assess fatigue from frequent vehicles, therefore, rare trucks with more than 5 axles are removed from the initial data.

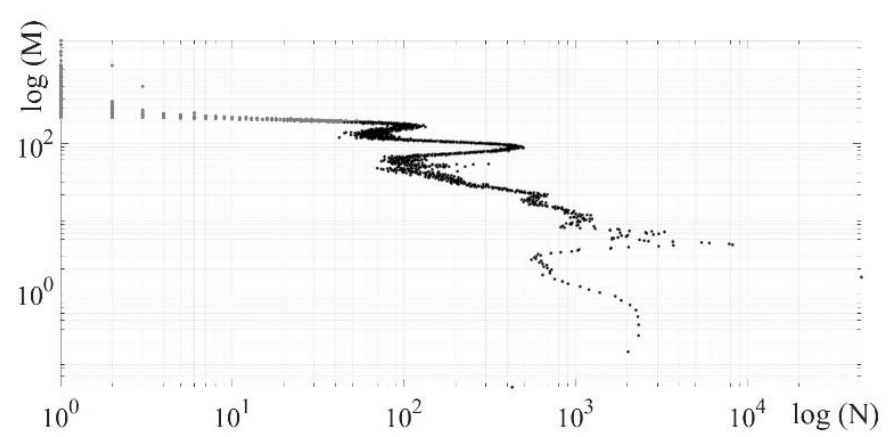

Figure 8 . Bending moments, $\mathrm{M}$, as a function of $\mathrm{N}$, log-scale

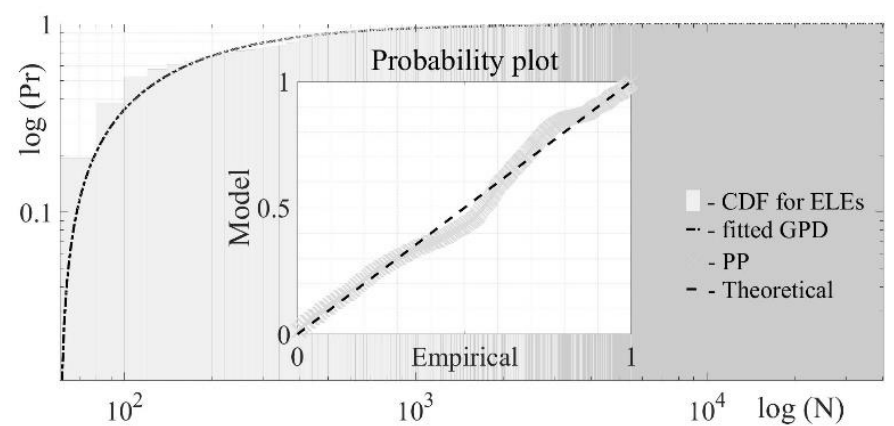

Figure 9.Fitting GPD to $\mathrm{N}$ with the model check, log-scale

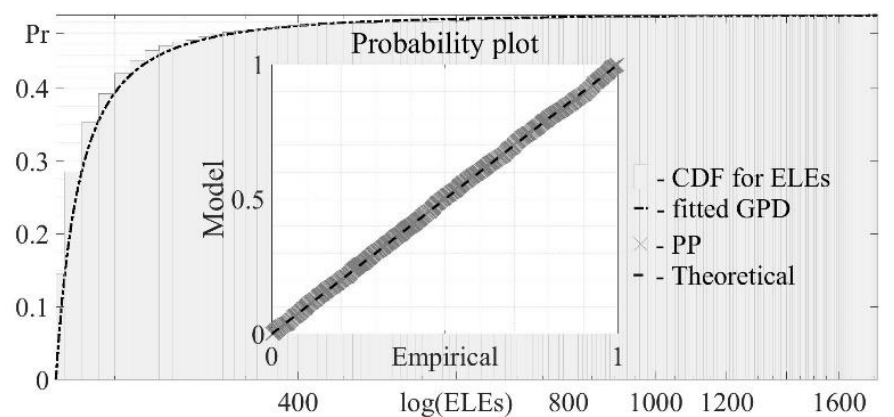

Figure 10. Fitting GPD to high amplitude LEs, with the model check, log-scale
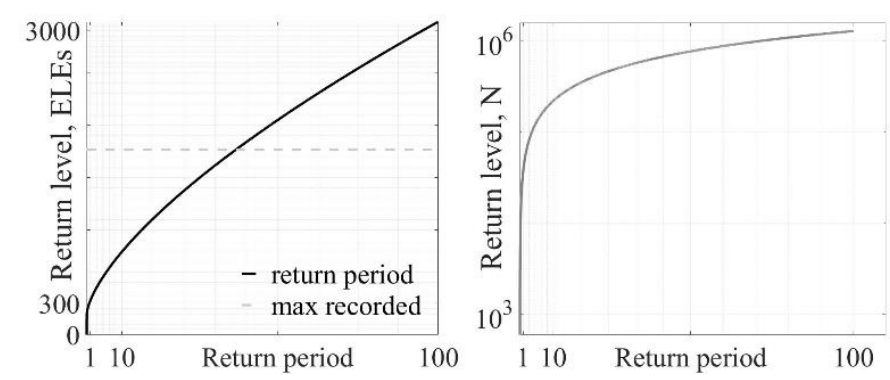

Figure 11. Return levels: for 'high amplitudes', M, kNm (left), for 'high cycles', $\mathrm{N}$ (right)

The distribution of all LEs is given in Figure 8. There are high amplitudes of LEs (in grey) that are treated by EVT and the approach explained in Section 2.2, the distribution of ELEs with the TH= $215 \mathrm{kNm}$ and the model check is shown on the figure 10, the estimated return period - in Figure 11. Compared with the fitting the GPD to N, it can be concluded that the approach is working the same way for different types of LEs: bending moments or number of cycles.

\subsection{Anneau bridge}

Overall, 303 days of monitoring were completed between August 2016 and July 2017. After the detailed analysis of received data, it was detected that the highest values of stresses appeared in the transversal rebar of the span 2. Therefore, this exact rebar is studied for the current paper. Here, the monitored data are represented by measured strain $(\varepsilon, \mu \mathrm{m} / \mathrm{m})$ directly in rebars, which allows assessing stresses easily knowing Young's modulus of steel $E=$ $210000 \mathrm{~N} / \mathrm{mm}^{2}=0,21 \mathrm{~N} / \mu^{2} \quad$ (EN 1993-1-1, 2005):

$$
\sigma=E \cdot \varepsilon, \quad[M P a]
$$

Fatigue cycles are counted using the "rainflow" method (ASTM E1049-85) that provides numbers of cycles for each stress amplitude (Fig. 12). To avoid the "noise" of the signal, all amplitudes under $1 \mathrm{MPa}$ were removed from calculations and the histogram of stress amplitudes of different ranges is shown in Figure 15.

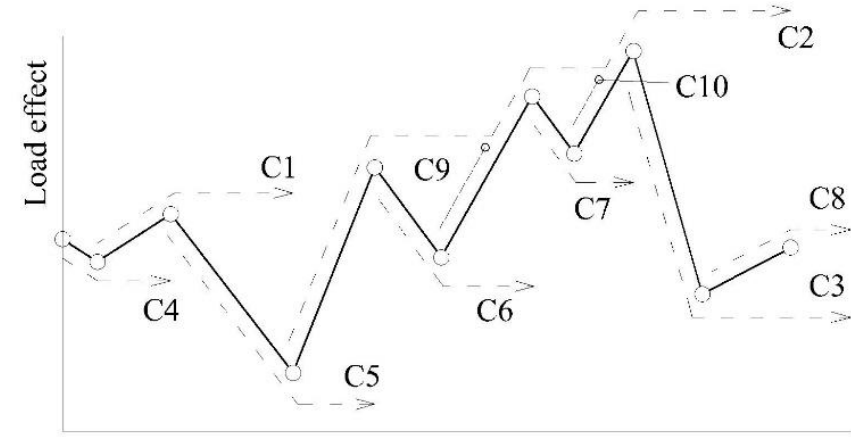

Figure 12. 'rainflow' counting 
Again, there are two possible cases: a large amount of cycles of small amplitude $(<10 \mathrm{MPa})$ and relatively rare high stresses $(>50 \mathrm{MPa})$.

The case of high stresses and their extrapolation in time is a question of the EVT and its classical application. As it was shown in the previous section, for the case of Millau. The GPD is fitted to all LEs (given here by stress cycles) as it was described in Section 2.4, fitting with the model check is shown in Figure 13.

Stress amplitudes that are smaller than $1 \mathrm{MPa}$ are removed from the distribution, assuming that such stress as the noise of the system. However, stresses over $1 \mathrm{MPa}$ represent cars passing or light trucks passing not exactly above the installed strain gauge. The high amplitude cycles, over $50 \mathrm{MPa}$, should be fitted to a different GPD since a number of cycles produced by them is too small (Fig. 14)

Assuming that the fitting is successful (according to the model check, Figure 13), parameters of the GPD can be normally used further for the estimation of return levels. However, in this case, the ratio between 'exceedances' and all effects is equal to one due to the absence of any threshold. What is interesting in the case of fatigue, the estimation of cycles at each range of stress amplitudes - Figure 15.

Though, the probability of occurrence of each range of $5 \mathrm{MPa}$ is found for the amount of data measured for 303 days (Fig. 16). Inserting these values into the formula, return levels are calculated for several values of the return period.

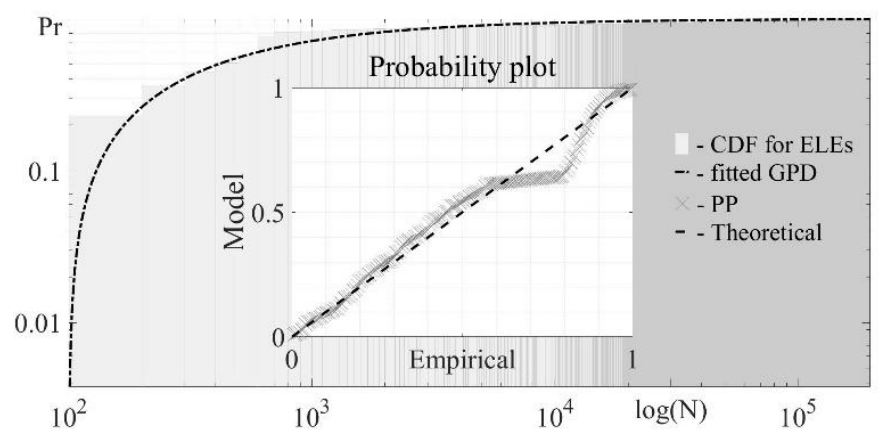

Figure 13. Fitting the GPD to $\mathrm{N}$ for stress range $1 \ldots 50 \mathrm{MPa}$

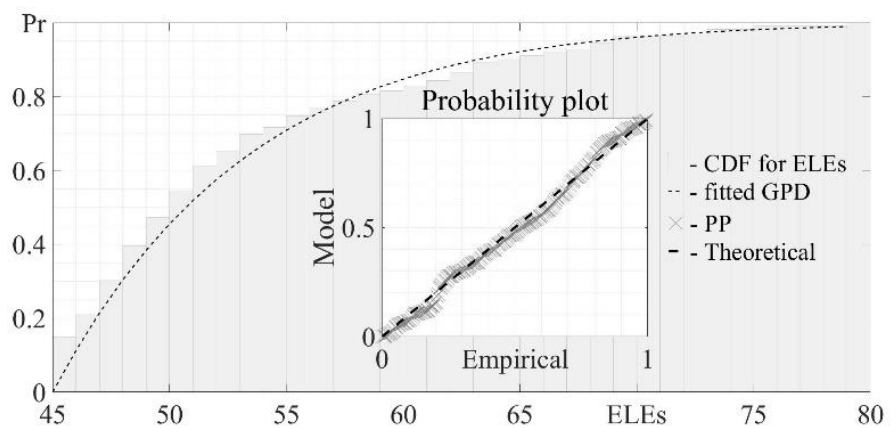

Figure 14. Fitting the GPD to LEs for a stress range over 45 $\mathrm{MPa}$

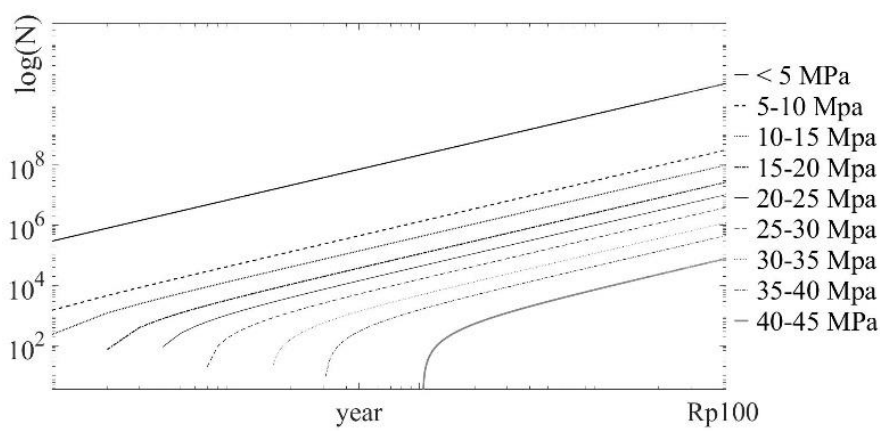

Figure 15. Return levels for different stress ranges, log-scale

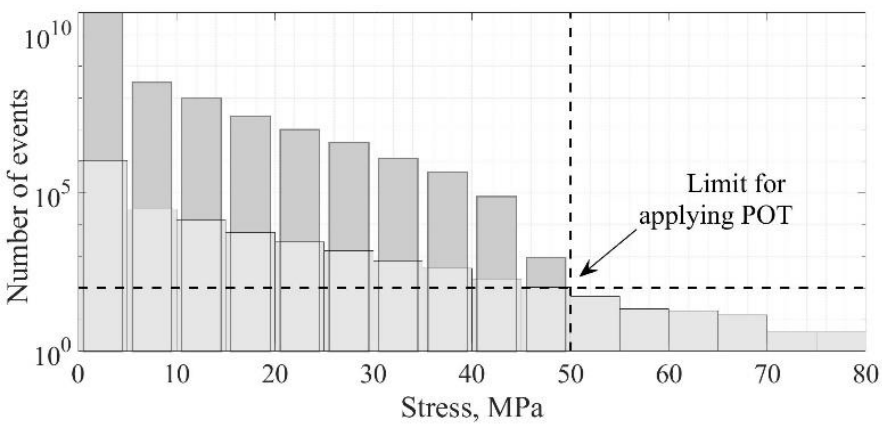

Figure 16. Stress spectrum from monitoring of 303 days (in grey), predictions in 100 years (in white)

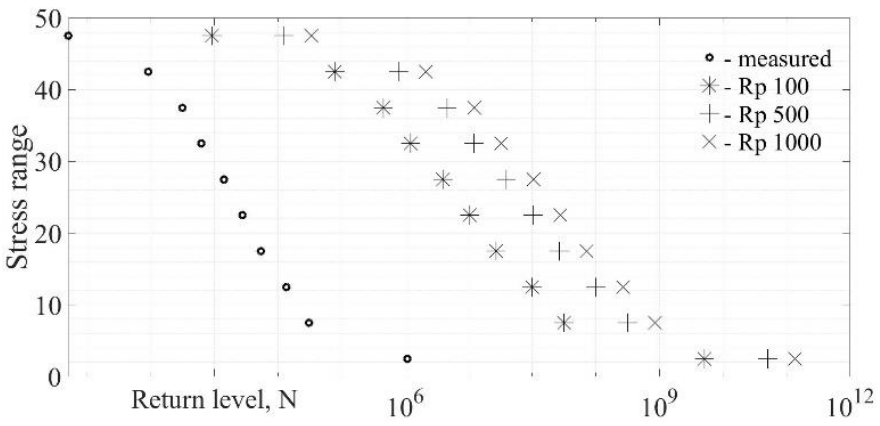

Figure 17. Estimated return periods of $\mathrm{N}$ in 100, 500, 1000 years, for each stress range

The method proposed in Section 2.4 is applied to the distribution of stress cycles with ranges each 5 $\mathrm{MPa}$. The results for return periods of 100, 500 and 1000 years are shown in the Figure 17.

Knowing that in this particular case, all observed stresses lay under the cut-off limit (EN 1993-1-9, 2005) of the S-N curve for steel reinforcement bars, the applied algorithm only provides the estimated numbers of cycles over certain return periods (Fig. 17). Studied stresses caused by traffic actions are not high enough to cause any fatigue danger even in 1000 years.

\section{CONCLUSIONS}

The algorithm of application of the Generalized Pareto Distribution to fatigue cycles is proposed in the current paper. Results of two studied examples of monitored objects (the Anneau bridge, Switzerland, 
and the Millau viaduct, France) permit the following summary:

- Monitoring data are required for long-term predictions of fatigue life. Moreover, demonstrated in the section 4.2 results for the Anneau bridge allow the following conclusion: measurements by strain gauges significantly simplify the study due to the direct access to stress ranges distribution.

- Estimation of return levels of N (number of cycles) at given period of time is possible using EVT and in particular, GPD with its parameters, however, more study of various objects is necessary to make more solid conclusions.

- The proposed algorithm works in described specific cases (one year of monitored stresses in the deck of the Anneau bridge and a half a year of recorded vehicles weights on the Millau viaduct), however, it does not show fatigue danger in perspective. Although, it might be applied to other structures with larger traffic volume.

Predicting the number of fatigue cycles in bridges is an actual topic of the modern research. Extending the service duration of existing bridges gives the motivation for novice theoretical approaches that are being proposed nowadays. The experimental part such as monitoring of real objects is undoubtedly useful for the developing of new mathematical models. It leads to the possibility of the application of the EVT for fatigue predictions. Since the traffic growth was not taken into account in the described method, as well, it requires further model uncertainties verification, the current study is being continued by authors.

\section{ACKNOWLEDGEMENT}

This project has received funding from the European Union's Horizon 2020 research and innovation programme under the Marie Sklodowska-Curie grant agreement No 676139. The grant is gratefully acknowledged.

The WIM measurements for the Millau viaduct were provided by EIFFAGE, France, and the data from monitoring of the Anneau bridge - by EPFL, Switzerland, which is highly appreciated.

\section{REFERENCES}

Adasooriya, 2016. Fatigue reliability assessment of ageing railway truss bridges: Rationality of probabilistic stress-life approach. Case Studies in Structural Engineering 6, pp. 110.

Agarwal, P. \& Lance, M., 2009. Simulation of offshore wind turbine response for long-term extreme load prediction. Engineering Structures 31, pp. 2236 - 2246.

Baptista, R. N., 2017. Probabilistic S-N curves for constant and variable amplitude. International Journal of Fatigue 00, pp. 1-19.
Cetin, Naess \& Härkegård, 2012. A physically based extreme value characterization of material fatigue. International Journal of Fatigue 47, pp. 216-221.

Coles, S., Bawa, J., Trenner, L. \& Dorazio, P., 2001. An introduction to statistical modeling of extreme values. s.l.:Springer.

Crespo-Minguillón, C. \& Casas, J. R., 1997. A comprehensive traffic load model for bridge safety checking. Structural Safety 19, pp. 339 - 359.

E1049-1985, A., 2005. Standard Practices for Cycle Counting in Fatigue Analysis. s.l.:s.n.

Echard, Gayton \& Bignonnet, 2013. A reliability analysis method for fatigue design. International Journal of Fatigue, pp. 292-300.

Pickands, J. I., 1975. Statistical inference using extreme order statistics. The Annals of Statistics 1, pp. 119-131.

Roth, M. et al., 2014. Projections of precipitation extremes based on a regional, non-stationary peaks-over-threshold approach: A case study for the Netherlands and northwestern Germany. Weather and Climate Extremes 4, pp. 110.

Sedlacek, Merzenich \& Paschen, 2008. Background document to EN 1991- Part 2 - Traffic loads for road bridges - and consequences for the design, s.l.: JRC Scientific and Technical Reports.

Shiri, S., Pourgol-Mohammad, M. \& Yazdani, M., 2016. Prediction of Remaining Fatigue Cycles in Composite Materials Under Uncertainty. Journal of Risk and Uncertainty in Engineering Systems Part B: Mechanical Engineering.

Sigauke, C. \& Bere, A., 2017. Modelling non-stationary time series using a peaks over threshold distribution with time varying covariates and threshold: An application to peak electricity demand. Energy 119, pp. 152-166.

Treacy, M. A., 2014. The use of monitored data in the verification of structural and fatigue safety of existing posttensioned concrete highway bridges. Lausanne: EPFL.

Yan, et al., 2017. Fatigue stress spectra and reliability evaluation of short- to medium-span bridges under stochastic and dynamic traffic loads. Bridge Engineering 22.

Zhou, X.-Y., Schmidt, F., Toutlemonde, F. \& Jacob, B., 2016. A mixture peaks over threshold approach for predicting extreme bridge traffic load effects. Probabilistic Engineering Mechanics 43, pp. 121 - 131.

Zhou, X. Y., 2013. PhD Thesis. Statistical analysis of traffic loads and their effects on bridges. Paris: Université ParisEst. 